\title{
Neonatal meningitis in England and Wales: a review of routine national data
}

\author{
Mary B Synnott, Dale L Morse, Susan M Hall
}

\begin{abstract}
The objective of this study was to describe trends in neonatal meningitis in England and Wales during the years 1975-91. Laboratory reports and, for the years 1983-91, data on statutory notifications and deaths from neonatal meningitis were reviewed.

The mean annual total of laboratory reports of neonatal bacterial meningitis 1975-91 was 109 cases (range 69-133) with a slight upward trend apparent in the latter half of the study period. The mean annual number of reports of neonatal viral meningitis was only 14 cases with no trend apparent. The leading bacteria isolated were group B streptococci, Escherichia coli, and Listeria monocytogenes accounting for $34 \cdot 1 \%, 28 \cdot 5 \%$, and $6 \cdot 8 \%$ of reports, respectively. There was a change in the pattern of causative bacteria from 1981 onwards with the group B streptococcus displacing $E$ coli as the leading cause. With respect to neonatal viral meningitis, echoviruses and coxsackie viruses accounted for $55.4 \%$ and $38.6 \%$ of cases, respectively. Neonatal meningitis was seriously undernotified; the ratio of laboratory reported cases to cases notified ranged from 12:1 in 1985 to $4: 1$ in 1989. The annual numbers of deaths ranged from 18 to 39 .

The laboratory reporting system provided the most useful data on secular trends and causative organisms for neonatal meningitis. The slight upward trend in the number of reports of bacterial meningitis merits continued surveillance. (Arch Dis Child 1994; 71: F75-F80)
\end{abstract}

Meningitis is an important cause of illness and death in infancy. It is more common in the neonatal period (under 28 days) than at any other time. In a retrospective study of acute bacterial meningitis in children in the North West Metropolitan region 1969-73, the incidence of meningitis in neonates was 0.26 per 1000 live births. ${ }^{1}$ In a two year (1985-7) prospective study of acute meningitis in England and Wales in infants, the incidence of meningitis during the 28 day neonatal period was 0.32 per 1000 live births (equivalent to annual incidence of 4.2 per 1000 ) compared with 1.22 per 1000 live births among post- neonatal infants from 28 days up to 1 year (equivalent to annual incidence of 1.3 per 1000). ${ }^{2}$ Risk factors reported for neonatal meningitis include prematurity and low birth weight, prolonged rupture of membranes, and maternal infection. 23

Changes in the spectrum of organisms causing neonatal meningitis during the last two decades have been reported in the US and Australia with the emergence of the group B streptococcus to overtake Escherichia coli as the leading cause. ${ }^{45} \mathrm{E}$ coli was the leading cause of neonatal meningitis in England and Wales in $1975-83^{6}$ while in a study from $1985-7$, the group B streptococcus was reported as the most frequent cause of neonatal bacterial meningitis. ${ }^{2}$ Higher case fatality rates have been reported for Gram negative organisms such as $E$ coli than for Gram positive organisms. ${ }^{78}$ Higher morbidity rates have not been consistently reported in neonatal Gram negative meningitis. In a review of neonatal meningitis cases in the US, there was no significant difference in morbidity rates in neonates infected with Gram negative rather than Gram positive organisms. ${ }^{8}$ By contrast, in a survey in Australia long term sequelae were significantly more common among survivors of Gram negative meningitis. ${ }^{5}$ An increase in the proportion of cases due to opportunistic pathogens attributed to changes in paediatric practice with intensive management of very low birthweight babies has been reported. ${ }^{5}$ Neurodevelopmental sequelae have been reported (most commonly deafness) in up to one third of survivors of neonatal meningitis. ${ }^{810}$ Despite advances in antibiotic treatment, little improvement in long term morbidity rates among survivors of neonatal meningitis has been reported in recent compared with earlier studies. ${ }^{8}$

High case fatality rates have been reported for neonatal meningitis, ranging from $66 \%$ in studies in the earlier part of the antibiotic era $^{11}$ to $20-50 \%$ in more recent studies in the UK ${ }^{1212}$ and other developed countries. ${ }^{78}$ A case fatality rate of $43 \%$ was reported by Goldacre $^{1}$ for neonates and $13 \%$ for postneonatal infants while de Louvois et al ${ }^{2}$ reported case fatality rates of $19.8 \%$ and $5.4 \%$ for neonates and postneonatal infants, respectively. Among cases of neonatal meningitis a significantly higher mortality has been reported in premature and low birthweight babies. $^{12}$ 


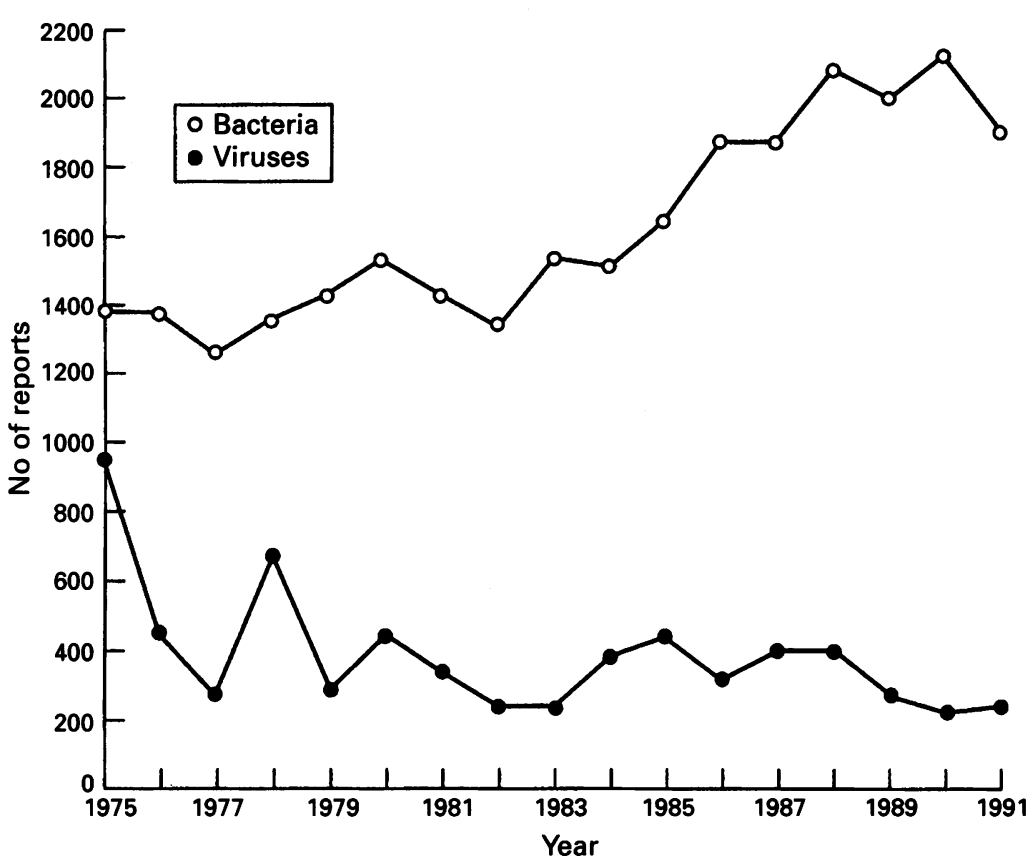

Figure 1 Meningitis: yearly number of laboratory reports; all ages England and Wales, 1975-91 (source CDSC).
Statutory notification data for neonates are not published in tables of Communicable Disease Statistics. ${ }^{13}$ Notification data on neonatal meningitis for the years 1983-91 were obtained by kind permission of the Office of Population Censuses and Surveys (OPCS). Notified cases of meningitis have been available by certain categories of organism since 1982; these are: meningococcal, pneumococcal, Haemophilus influenzae, viral, other specified organisms, and unspecified.

Neonatal meningitis death data for 1983-91 in this review were obtained from OPCS. Because of a change in the form for registration, data for 1983-5 were for an underlying cause of death and for 1986-91 data were for a main fetal cause of death. ${ }^{14} 15$ Data on deaths coded as bacterial meningitis were available by certain categories of organism as follows: haemophilus, pneumococcal, streptococcal, staphylococcal, other specified bacteria, and unspecified bacterium. There were individual codes for meningococcal meningitis and tuberculous meningitis.

\section{Results}

The purpose of this paper was to summarise the routine national data on neonatal meningitis in England and Wales 1975-91 in order to extend an earlier review ${ }^{6}$ and to examine the possible effects on trends of the increasing numbers of premature and low birthweight babies resulting from modern obstetric and neonatal practice.

\section{Methods}

Data provided from voluntary laboratory reports to the PHLS Communicable Disease Surveillance Centre (CDSC) for the years 1975-91 were reviewed. Laboratory reports of bacterial meningitis were cases confirmed by positive cerebrospinal fluid culture or by detection of bacterial antigen (meningococcal, pneumococcal, or haemophilus) in the cerebrospinal fluid. For viral meningitis, the virus was identified in the cerebrospinal fluid. Laboratory data on neonatal meningitis were compared with data on meningitis at all other ages.

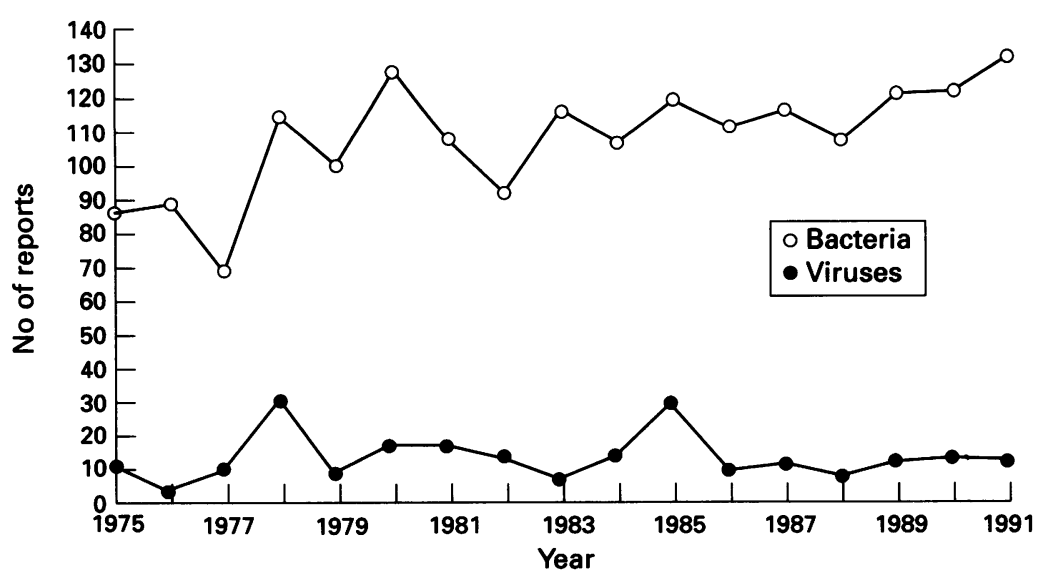

Figure 2 Meningitis: yearly number of laboratory reports; neonates England and Wales, 1975-91 (source CDSC).
ANNUAL TRENDS: ALL AGES

During the study period, the annual totals of laboratory reports on bacterial meningitis at all cases in 1991 with a mean of 1624 cases. There was an upward trend in reports of bacterial meningitis (fig 1); the mean annual number of reported cases during the time period 1975-82 was 1386 compared with a mean annual number of 1834 during the period 1983-91. The annual number of laboratory reports of viral meningitis ranged from 958 cases in 1975 to 242 cases in 1991 with a mean of 388 cases. There was a slight downward trend in reports of viral meningitis (fig 1); the mean annual number of reported cases during the time period 1975-82 was 458 cases compared with a mean annual number of 326 cases during the period 1983-91.

ANNUAL TRENDS: NEONATES

The mean annual number of reports of neonatal bacterial meningitis during the 17 year study period was 109 cases (range 69-133). There was a slight male preponderance with $52 \%$ (967 reports) of bacterial meningitis cases in males, $40 \%$ (739 reports) in females, and $8 \%$ (140 reports) of cases in which sex was not recorded. There was a slight upward trend: for the years 1975-82, the mean annual number of cases was 112 compared with a mean annual number of 131 cases for 1983-91, a $17 \%$ increase (fig 2). The mean annual number of reports of neonatal viral meningitis was only 14 cases (range 3-31) with no trend apparent.

The proportion contributed by neonates to the total numbers of laboratory reports of cases of bacterial meningitis was fairly constant between $5.2 \%$ and $9.3 \%$ during the study period. For viral meningitis, the proportion contributed by neonates varied more widely from $0 \cdot 7 \%$ to $8 \cdot 7 \%$. ages ranged from 1385 cases in 1975 to 1896 
Table 1 Laboratory reports of bacterial meningitis: England and Wales, 1975-91 (bacteria identified in cerebrospinal fluid and blood); figures are total (\%)

\begin{tabular}{lcc}
\hline Organisms or group & Neonates & All other ages \\
\hline Group B streptococcus & $633(34 \cdot 3)$ & $368(1 \cdot 4)$ \\
Escherichia coli & $526(28 \cdot 5)$ & $523(2 \cdot 0)$ \\
Listeria monocytogenes & $125(6 \cdot 8)$ & $448(1 \cdot 7)$ \\
Streptococcus pneumoniae & $98(5 \cdot 3)$ & $5025(19 \cdot 5)$ \\
Other streptococci (excluding & & \\
S pneumoniae) & $59(3 \cdot 2)$ & $538(2 \cdot 1)$ \\
Neisseria meningitidis & $50(2 \cdot 7)$ & $8870(34 \cdot 4)$ \\
Proteus sp & $44(2 \cdot 4)$ & $84(0 \cdot 3)$ \\
Staphylococcus aureus & $43(2 \cdot 3)$ & $612(2 \cdot 4)$ \\
Klebsiella sp & $42(2 \cdot 3)$ & $159(0 \cdot 6)$ \\
Haemophilus influenzae & $42(2 \cdot 3)$ & $7200(27 \cdot 9)$ \\
Pseudomonas sp & $39(2 \cdot 1)$ & $170(0 \cdot 7)$ \\
Enterobacter sp & $28(1 \cdot 5)$ & $65(0 \cdot 3)$ \\
Staphylococcus epidermidis/albus & $28(1 \cdot 5)$ & $586(2 \cdot 3)$ \\
Citrobacter sp & $21(1 \cdot 1)$ & $12(<0 \cdot 1)$ \\
Salmonella sp & $18(0 \cdot 9)$ & $55(0 \cdot 2)$ \\
Serratia sp & $15(0 \cdot 8)$ & $23(0 \cdot 9)$ \\
Coagulase negative staphylococci & $14(0 \cdot 8)$ & $124(0 \cdot 5)$ \\
Mycobacteria & 0 & $433(1 \cdot 7)$ \\
Other & 21 & $462(1 \cdot 8)$ \\
Total & $1846(100)$ & $25757(100)$ \\
\hline
\end{tabular}

*Includes Acinetobacter sp (4), Bacteroides sp (3), Clostridium sp (3), coliforms (3), Pasteurella sp (3), achromobacter/alcaligenes (2), Haemophilus parainfluenzae (1), Corynebacterium sp (1), Flavobacterium sp (1).

\section{CAUSATIVE ORGANISMS}

\section{(1) Laboratory data}

(A) Bacteria - Group B streptococci and $E$ coli were the most commonly reported bacterial isolates from cases of neonatal meningitis, accounting for $34 \cdot 1 \%$ (633 reports) and $28.5 \%$ (526 reports), respectively, for all reports (table 1). By contrast, these organisms accounted for only $14 \%$ and $2 \%$ of reports of cases at all other ages. Listeria monocytogenes was the reported isolate from 125 cases $(6 \cdot 8 \%)$ of neonatal meningitis. More cases of neonatal bacterial meningitis were reported in males than females $(52 \%$ male; $40 \%$ female; $8 \%$ unknown). The sex distribution for group B streptococcal cases (48\% male; $44 \%$ female; $8 \%$ unknown) and $L$ monocytogenes ( $47 \%$ male;

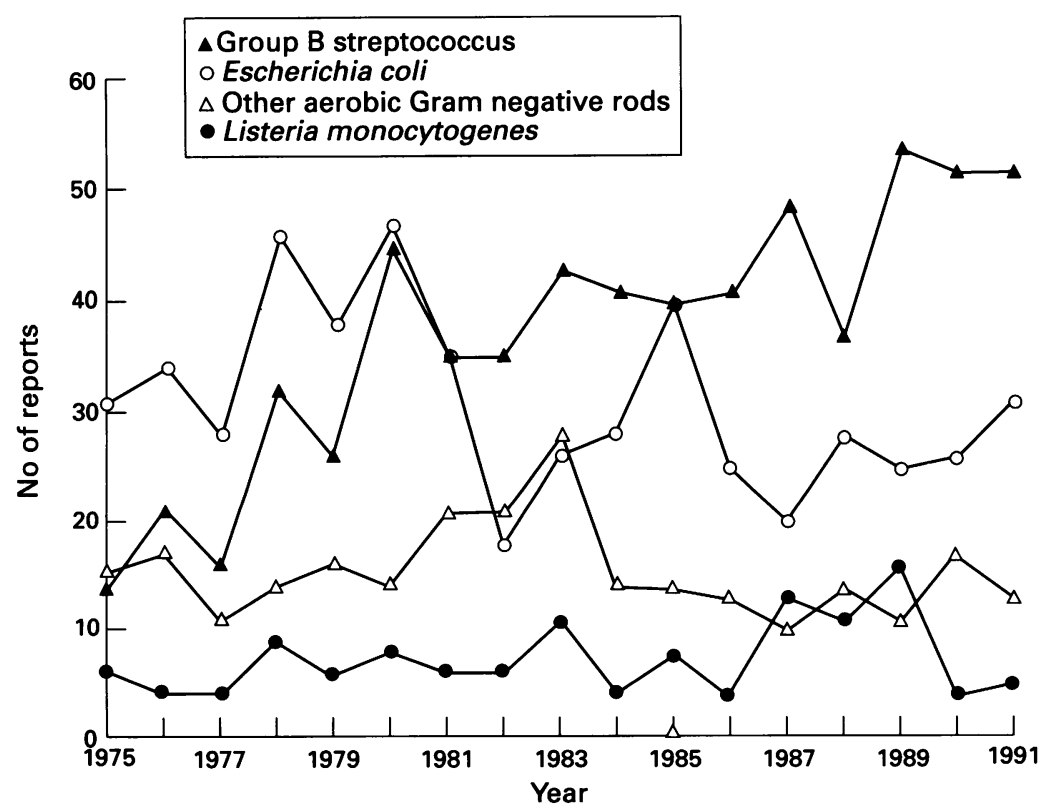

Figure 3 Secular trends of neonatal bacterial meningitis; laboratory reports from England and Wales, 1975-91 (source CDSC).
$46 \%$ female; $7 \%$ unknown) was fairly even. By contrast, there was a striking male preponderance for $E$ coli cases ( $57 \%$ male, $36 \%$ female; $7 \%$ unknown). Streptococcus pneumoniae (pneumococcus) which was the reported isolate from $19 \cdot 5 \%$ of cases at all other ages was reported in only 5.3\% (98 reports) of cases of neonatal meningitis. Neisseria meningitidis and $H$ influenzae, the commonest causes of bacterial meningitis at all other ages accounted for only $2 \cdot 7 \%$ (50 reports) and $2 \cdot 3 \%$ (42 reports) of reported isolates from cases of neonatal meningitis (table 1). Several other organisms such as staphylococci and aerobic Gram negative rod species (other than $E$ coll) were uncommonly isolated and each accounted for between $0.8 \%$ and $2 \cdot 4 \%$ of isolates from cases of neonatal meningitis. With respect to the aerobic Gram negative rods, for all species a higher proportion of these cases occurred in neonates than at all other ages (table 1).

Secular trends - During the time period 1975-80, the most frequently reported bacterial isolate was $E$ coli with group B streptococcus the second most frequently reported isolate (fig 3). In 1981, the number of reports of group B streptococcus was equal to that of $E$ coli. From 1981 onwards, the general trend was an increase in the number of reports of Group B streptococcus and a decrease in the number of reports of $E$ coli. From 1982 onwards, the annual number of reports of group B streptococcus exceeded that of $E$ coli for each year of the study period with the exception of 1985 when the numbers were equal. There was a slight increase in the numbers of reports of aerobic Gram negative rods during the years 1981-3; otherwise the pattern was fairly stable. The number of

Table 2 Laboratory reports of neonatal viral meningitis: England and Wales, 1975-91

\begin{tabular}{|c|c|c|}
\hline Virus & No of cases & Total No (\%) \\
\hline \multicolumn{2}{|l|}{ Coxsackie A total } & $15(6 \cdot 4)$ \\
\hline A2 & 1 & \\
\hline A7 & 1 & \\
\hline A9 & 13 & \\
\hline A19 & 0 & \\
\hline A21 & 0 & \\
\hline A untyped & 0 & \\
\hline \multicolumn{2}{|l|}{ Coxsackie B total } & $75(32 \cdot 2)$ \\
\hline B1 & 2 & \\
\hline B2 & 20 & \\
\hline B3 & 12 & \\
\hline B4 & 22 & \\
\hline B5 & 16 & \\
\hline B6 & 2 & \\
\hline B group & 1 & \\
\hline \multicolumn{2}{|l|}{ Echovirus total } & $129(55 \cdot 4)$ \\
\hline 3 & 1 & \\
\hline 4 & 1 & \\
\hline 6 & 12 & \\
\hline 7 & 22 & \\
\hline 9 & 17 & \\
\hline 11 & 54 & \\
\hline 14 & 1 & \\
\hline 17 & 3 & \\
\hline 18 & 3 & \\
\hline 19 & 4 & \\
\hline 20 & 1 & \\
\hline 22 & 2 & \\
\hline 24 & 1 & \\
\hline 25 & 1 & \\
\hline 30 & 6 & \\
\hline \multicolumn{2}{|l|}{ Herpes simplex } & $10(4 \cdot 3)$ \\
\hline \multirow{2}{*}{\multicolumn{2}{|c|}{$\begin{array}{l}\text { Mumps } \\
\text { Cytomegalovirus }\end{array}$}} & $3(1 \cdot 3)$ \\
\hline & & $1(0 \cdot 4)$ \\
\hline \multicolumn{2}{|l|}{ Other viruses } & \\
\hline \multicolumn{2}{|l|}{ Total reports } & $233(100)$ \\
\hline
\end{tabular}




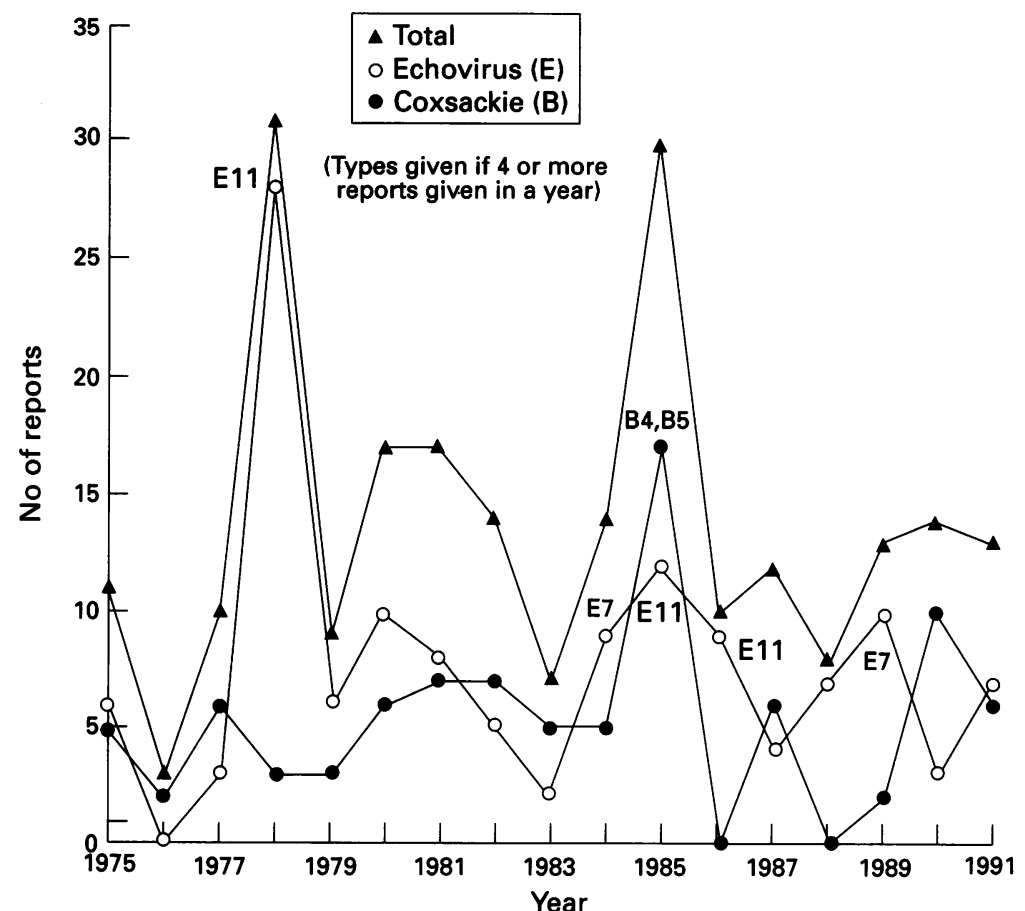

Figure 4 Secular trends of neonatal viral meningitis; laboratory reports from England and Wales, 1975-91 (source CDSC).

reports of $L$ monocytogenes each year was small and fairly constant (between four and 11); the peak number of reports was 16 in 1989 with only four cases being reported in 1990 and five in 1991 .

(B) Viruses - During the time period 1975-91, there were 233 laboratory reports of cases of neonatal virus meningitis; 119 cases were reported during the period $1975-83$ and 114 cases during 1984-91. The echoviruses and coxsackie viruses were the commonest reported organisms, accounting for $55.4 \%$ and $38.6 \%$ of cases respectively (table 2 ) and echovirus type 11 and coxsackie viruses $\mathrm{B} 2$ and B4 were the most frequently reported types with marked peaks in some years (for example 1978 and 1985; fig 4).

\section{(2) Notification data}

The total number of statutory notifications of neonatal meningitis each year was small. The mean annual number of notifications during the time period 1983-91 was 23 compared with a mean annual number of laboratory reports (of bacterial and viral meningitis) during the same time period of 131 cases. From 1988 onwards, there was a slight upward trend in the number of notifications which was in parallel with the slight increase in the number of laboratory reports. The ratio of laboratory reported cases to cases notified ranged from 12:1 in 1985 to approximately $4: 1$ in 1989. The numbers of notifications broken down by category of organism each year were too small to conduct an analysis of secular trends.

\section{(3) Mortality data}

During the time period 1983-91, there were 249 certified neonatal meningitis deaths. The annual numbers of deaths varied from 18 to 39. The mortality rate per 1000 live births attributed to neonatal meningitis ranged from a minimum of 0.03 in 1985 to a maximum of 0.06 in 1987 . One hundred and seventy five deaths $(70 \%)$ were coded bacterial meningitis and 65 deaths $(26 \%)$ were coded meningitis due to unspecified causes. One hundred and fifty of the $175(85.7 \%)$ bacterial meningitis deaths were coded to an organism subcategory; $52(52 / 175$ or $29.7 \%)$ deaths were coded 'streptococcal', 17 (17/175 or $9 \cdot 7 \%)$ deaths 'pneumococcal', one ( $1 / 175$ or $0.006 \%)$ each 'staphylococcal' and 'haemophilus', 53 $(53 / 175$ or $30.3 \%)$ deaths 'other specified bacterium', and $26(26 / 175$ or $14.9 \%)$ deaths were coded 'unspecified bacterium'.

\section{Discussion}

In a previous review of neonatal meningitis in England and Wales, ${ }^{6}$ the laboratory reporting system provided useful data on secular trends between 1975 and 1983 and on causative organisms whereas notification and mortality data were less helpful. In this study, laboratory reports, from 1975-91 were analysed while notification and mortality data only for the years 1983-91 were included. During 1983-91, the total number of laboratory reports of neonatal bacterial and viral meningitis each year (mean =131) was four to five times greater than the number of statutory notifications $($ mean $=23)$. Serious undernotification of meningitis in the UK has been previously reported. ${ }^{16-18}$ The completeness of notification rates has varied by the type of meningitis; the best rates were reported for meningococcal meningitis $(50 \%-65 \%)$ and the poorest for viral meningitis $(2 \%)$.

Mortality rates for neonatal meningitis were fairly constant $(0.03$ to 0.06 per 1000 live births) between 1983 and 1991 and a little lower than the rates (ranging from 0.045 to 0.09 per 1000 live births) recorded in the earlier time period of 1975-82. However, mortality data were not helpful in examining secular trends for two reasons. Firstly, the number of neonatal deaths each year was small $($ mean $=28)$. Secondly, a change in the neonatal death certificate was introduced in 1986 with the result that neonatal deaths were no longer coded by underlying cause of death; therefore, pre-1986 neonatal mortality data were not directly comparable with data from 1986 onwards.

While the laboratory reporting system is more complete than the notification and mortality data bases, it also misses some cases of meningitis. All cases are not investigated and diagnosed. Goldacre reported that $29 \%$ of cases of acute bacterial meningitis in childhood were undiagnosed until necropsy. ${ }^{1}$

De Louvois et al identified 423 cases of neonatal meningitis in England and Wales during a two year period (from September 1985-August 1987) in a prospective study using an active case ascertainment method: 400 cases were identified using monthly inquiry cards completed by paediatricians and 
an additional 23 cases were identified from CDSC, the Meningococcal Reference Laboratory, and OPCS data. ${ }^{2}$ Excluding the 92 cases $(22 \%)$ in which the cerebrospinal fluid was sterile or not collected, the remaining 331 should have been detectable through the national voluntary laboratory reporting system. During the calendar years 1985 and 1986 , there were a total of 274 laboratory reports of neonatal meningitis which represented approximately $83 \%(274 / 331)$ of cases identified through the active surveillance scheme. Assuming that the degree of laboratory underreporting of cases has remained fairly constant during the study period, it is therefore valid to use this data source to analyse trends over time.

During 1975-91, the leading causes of neonatal bacterial meningitis were the group $B$ streptococcus $(34 \cdot 1 \%)$ and $E$ coli $(28 \cdot 5 \%)$ which accords with the patterns of causative organisms reported from the $\mathrm{UK}^{2}{ }^{2}$ the US, ${ }^{4}$ and Australia. ${ }^{5}$ A slight male preponderence among neonatal meningitis cases was reported in some studies ${ }^{346}$ but not others. ${ }^{5}$ An equal male:female sex ratio for group B streptococcus and a male preponderance for $E$ coli neonatal meningitis cases was shown consistent with the previous report. ${ }^{6}$ During the early years of the study period $1975-80$ the numbers of reports of $E$ coli exceeded that of group B streptococcus; however, from 1982 onwards, the numbers of reports of group B streptococcus each year (with the exception of 1985) have consistently exceeded that of $E$ coli. The reasons for this change in pattern of causative organism in England and Wales (and the parallel change in the US ${ }^{19}$ ) is not known; $L$ monocytogenes accounted for $6.8 \%$ of cases (125 reports) which was consistent with the proportions $(2 \%-6 \cdot 7 \%)$ of neonatal bacterial meningitis cases due to this organism in previous studies in the UK, ${ }^{26}$ the Netherlands, ${ }^{7}$ and Australia. ${ }^{8}$ The number of reports of $L$ monocytogenes neonatal meningitis each year was small; however, there was an increase in the numbers of reports in 1987-9 and then a decrease. This trend mirrored the national pattern of a sharp increase in reported cases of human listeriosis between 1986 and 1987, which continued until 1989 after which there was a sharp decline. There was evidence that contaminated paté was the most likely contributory cause of the increase in incidence between 1987 and $1989 .{ }^{20}$

The classical leading bacterial causes of meningitis in older children and adults $(N$ meningitidis, $H$ influenzae, and $S$ pneumoniae) were relatively uncommon causes of neonatal meningitis each accounting for only between $2 \%-5 \%$ of cases. Remaining cases were accounted for by a wide variety of opportunistic organisms such as species of aerobic Gram negative rods (for example, proteus, klebsiella, enterobacter) and Gram positive organisms (for example, staphylococci). The increase in the numbers of reports of cases due to aerobic Gram negative rods (other than $E$ coli) noted in the earlier review ${ }^{6}$ has not been sustained. This may reflect better standards of care in special care and neonatal intensive care baby units and the availability of more potent antibiotics for use in prophylaxis to cover invasive procedures. Reports of anaerobic Gram negative rods were exceedingly rare; there were only three reports $(3 / 1846$ or $0.001 \%)$ during the study period.

For reasons already outlined, notification and mortality data were not helpful in studying trends in neonatal virus meningitis and therefore only laboratory reports were analysed. There was no evidence of any change in the overall pattern of neonatal virus meningitis; $94 \%$ of all cases were accounted for by the echo and coxsackie viruses. Coxsackie virus types B2 and B4 and echovirus types 7, 9, and 11 were the most frequently reported types with marked peaks in some years which coincided with national epidemics, for example, echovirus type 11 peaks in 1977 and in 1985-6.21 The lack of any increasing trend contrasts with the findings of a 15 year survey in the US. ${ }^{22}$

The total numbers of laboratory reports of neonatal virus meningitis for $1975-83$ in this review was 119 compared with 175 previously reported for the same time period. ${ }^{6}$ In the current study, only reports of identification of a virus in the cerebrospinal fluid were included while the earlier study included additional cases of clinical meningitis in which there was a fourfold rise in virus antibody titre or significant viral isolation from another site.

While improvements in early detection and antibiotic treatment of neonatal meningitis have resulted in reduction in case fatality rates, there has been little impact on morbidity in terms of long term neurological handicap. ${ }^{8}$ Therefore, a focus on prevention of neonatal meningitis is necessary.

Group B streptococcal disease is potentially preventable with antibiotic prophylaxis or immunisation in women of childbearing age. Intrapartum chemoprophylaxis for pregnant women at risk of delivering infants with group B streptococcal disease has been effective in prevention of early onset (occurring in infants $<7$ days old) neonatal group B streptococcal disease. ${ }^{19} 23$ However, meningitis occurs more commonly in late onset than early onset neonatal group B streptococcal disease. ${ }^{19}$ Prevention of late onset neonatal group B streptococcal meningitis depends upon the development of effective, multivalent group B streptococcus vaccines. The feasibility of protecting neonates from systemic group B streptococcal disease through active maternal immunisation with a type III capsular polysaccharide group B streptococcus vaccine preparation has been demonstrated.$^{24}$ However, the immunogenicity of the preparation was not optimal and work is still in progress to develop an ideal group B streptococcus vaccine.

Factors determining susceptibility and immunity of neonates to $E$ coli disease have been less extensively studied than group B streptococcus but $E$ coli disease is theoretically preventable by maternal immunisation or by passive immunisation ${ }^{25}$; however, suitable vaccine preparations are not yet available. 
With respect to $L$ monocytogenes, the incidence of infections can be reduced by pregnant women adhering to advice to reheat thoroughly cook-chill foods, and to avoid eating soft cheese and paté. ${ }^{26} 27$

High standards of infection control are essential in hospital baby units to minimise the risk of nosocomial spread of organisms such as group B streptococcus, ${ }^{28} \mathrm{~L}$ monocytogenes, ${ }^{29}$ and enteroviruses ${ }^{30}$ causing outbreaks of neonatal meningitis. With the increasing numbers of preterm and low birthweight babies consequent on modern obstetrics these measures are becoming even more important. However, the secular trends demonstrated by this study, particularly of organisms associated with the complications of neonatal intensive care, are encouraging, although the slight increase merits continued careful surveillance.

We wish to thank Dr A McCormick, senior medical statistician, mortality and for helpful discussions and Mr A Grant, CDSC for provision of data on laboratory reports.

1 Goldacre MJ. Acute bacterial meningitis in childhood. Incidence and mortality in a defined population. Lancet 1976; i: 28-31.

2 De Louvois J, Blackbourn J, Hurley R, Harvey D. Infantile meningitis in England and Wales: a two year study. Arch Dis Child 1991; 66: 603-7.

3 Hristeva L, Booy R, Bowler I, Wilkinson AR. Prospective surveillance of neonatal meningitis. Arch Dis Child 1993; 69: 14-8.

4 Wenger JD, Hightower AW, Facklam RR, Gaventa S, Broome CV. Bacterial meningitis study group. Bacterial meningitis in the United States, 1986: report of a multistate surveillance study. F Infect Dis 1990; 162:
1316-23.

5 Francis BM, Gilbert GL. Survey of neonatal meningitis in Australia: 1987-1989. Med $f$ Aust 1992; 156: 240-3.

6 PHLS report. Neonatal meningitis: a review of routine national data 1975-1983. BMभ 1985; 290: 778-9.

7 Mulder CJ, Zanen HC. A study of 280 cases of neonatal meningitis in the Netherlands. $\mathcal{F}$ Infect 1984; 9: 177-84.

8 Franco SM, Cornelius VE, Andrews BF. Long-term outcome of neonatal meningitis. Am $\mathcal{F}$ Dis Child 1992; 146: 567-71.
9 Mulhall A, de Louvois J, Hurley R. Efficacy of chloramphenicol in the treatment of neonatal and infantile meningitis: a study of 70 cases. Lancet 1983; i: 284-7.

10 Fortnum HM. Hearing impairment after bacterial meningitis: a review. Arch Dis Child 1992; 67: 1128-33.

11 Groover RV, Sutherland JM, Landing BH. Purulent meningitis of newborn infants. Eleven-year experience in the antibiotic era. N Engl f Med 1961; 264: 1115-21.

12 Bell AH, Brown D, Halliday HL, McClure G, McReid M. Meningitis in the newborn - a 14 year review. Arch Dis Child 1989; 64: 873-4.

13 Office of Population Censuses and Surveys. Communicable disease statistics. London: HMSO, 1983-91. (Series MB2.)

14 Office of Population Censuses and Surveys. Mortality statistics: perinatal and infant (social and biological factors). London: HMSO, 1983-91. (Series DH3.)

15 Office of Population Censuses and Surveys. Mortality statistics: cause. London: HMSO, 1983-5. (Series DH2.)

16 Goldacre MJ, Miller DL. Completeness of statutory notification for acute bacterial meningitis. $B M \mathcal{F} 1976$; ii: 501-3.

17 Cartwright KA, Stuart JM, Noah ND. An outbreak of meningococcal disease in Gloucestershire. Lancet 1986; ii: 558-61.

18 Harvey IM, Palmer SR, Peters TJ. Meningitis: can we trust the statistics? Health Trends 1989; 21: 73-6.

19 Zangwill KM, Schuchat A, Wenger JD. Group B streptococcal disease in the United States, 1990: report from a multistate active surveillance system. MMWR 1992; 41 (suppl 6): 25S-32S.

20 McLauchlin J, Hall SM, Velani SK, Gilbert RJ. Human listeriosis and paté: a possible association. BMF 1991; 303: 773-5.

21 Anonymous. Echovirus surveillance. Communicable Disease Report 1992; 2 (28): 125.

22 Shattuck KE, Chonmaitree T. The changing spectrum of neonatal meningitis over a fifteen-year period. Clin Pediatr (Phila) 1992; 31: 130-6.

23 Boyer KM, Gotoff SP. Prevention of early-onset neonatal group B streptococcal disease with selective intrapartum chemoprophylaxis. N Engl f Med 1986; 314: 1665-9.

24 Baker CJ, Rench MA, Edwards MS, Carpenter RJ, Hays BM, Kasper DL. Immunisation of pregnant women with a polysaccharide vaccine of group B streptococcus. N Engl f Med 1988; 319: 1180-5.

25 Ferrieri P. Neonatal susceptibility and immunity to major bacterial pathogens. Rev Infect Dis 1990; 12 (suppl 4): 394-400.

26 Department of Health. Advice from the Chief Medical Officer: listeriosis and food. London: DoH, 1989. (DoH PLCMO (89) 3 ; 16 Feb.)

27 Department of Health. Advice to vulnerable groups on paté stands. London: DoH, 1989. (DoH press release 89/369; 24 Aug.)

28 Mulder CJ, Zanen HC. Neonatal group B streptococcal meningitis. Arch Dis Child 1984; 59: 439-43.

29 Kessler SL, Dajani AS. Listeria meningitis in infants and children. Pediatr Infect Dis ₹ 1990; 9: 61-3.

30 Anonymous. Echovirus surveillance. Communicable Disease Report 1991; 1 (42): 191. 